\title{
Vaginal Lactobacillus: biofilm formation in vivo - clinical implications
}

\author{
This article was published in the following Dove Press journal: \\ International Journal of Women's Health \\ 16 February 2015 \\ Number of times this article has been viewed
}

\section{Gary Ventolini}

School of Medicine, Texas Tech University Health Sciences Center Permian Basin, Odessa, TX, USA
Correspondence: Gary Ventolini School of Medicine, Texas Tech University Health Sciences Center Permian Basin, 800 West Street Odessa, TX 79763, USA

Tel +l 4327035134

Email gary.ventolini@ttuhsc.edu

\begin{abstract}
Vaginal lactobacilli provide protection against intrusive pathogenic bacteria. Some Lactobacillus spp. produce in vitro a thick, protective biofilm. We report in vivo formation of biofilm by vaginal Lactobacillus jensenii. The biofilm formation was captured in fresh wetmount microscopic samples from asymptomatic patients after treatment for recurrent bacterial vaginitis. In vivo documentation of biofilm formation is in our opinion noteworthy, and has significant clinical implications, among which are the possibility to isolate, grow, and therapeutically utilize lactobacilli to prevent recurrent vaginal infections and preterm labor associated with vaginal microbial pathogens.
\end{abstract}

Keywords: vaginal Lactobacillus, biofilm, vaginal flora, vaginal, bacterial, protection

\section{Introduction}

Biofilms are particularly complex biological conglomerate structures where bacteria commonly thrive. Bacterial biofilm enables microorganisms to adhere to one another, to surfaces or to interfaces. ${ }^{1}$

The formation of biofilm is a refined process that involves two foremost divided steps: first, bacterial aggregation and recognition of surface-related stimuli that enables the adhesion of the microorganism to a surface, and second, a matrix biofilm formation and buildup production. ${ }^{1}$

The biofilm is responsible for maintaining an ecological unit in a stable state. When the bacteria involved are nonpathogenic, this event is considered to be advantageous, because it supports the establishment and long-term permanence of such bacteria. Furthermore, as in the case of vaginal lactobacilli, it seems to provide protection against intrusive pathogenic bacteria. ${ }^{2}$

It has been established that lactobacilli acquired from vaginal biopsy samples of healthy women may form biofilm in vitro. ${ }^{3}$ In the current medical literature, biofilm formation in fresh wet-mount vaginal preparations in vivo has not been reported.

The present report discusses the in vivo formation of biofilm by vaginal lactobacilli. The formation of biofilm was captured in fresh wet-mount microscopic vaginal preparations. These preparations were obtained from patients with a history of recurrent bacterial vaginitis, after appropriate antibiotic treatment was completed. Therefore, patients were at the time asymptomatic.

\section{Patients and methods}

Patients comprised those with recurrent vaginal infections who consulted our specialized clinic and consented to vulvovaginal evaluation and assessment, including vaginal sampling for bacterial and fungal cultures. Additionally, normal saline fresh wet-mount optic 
microscopy preparation was performed, and simultaneously photographic documentation was obtained and archived.

Furthermore, normal saline fresh wet-mount optic microscopy preparation and microscopic photograph documentation (MPD) were repeated after the microbiology diagnosis and medical therapy were completed. Moreover, this process was repeated after a negative test of cure was attained.

Our clinic is a faculty-affiliated practice within the Texas Tech Health Sciences Center at the Permian Basin, in the cities of Odessa and Midland, Texas. Bacterial cultures included Ureaplasma urealyticum, Mycoplasma hominis, and group B streptococci. Our database of MPD contained more than 600 photos and included more than 235 patients with positive bacterial culture.

Fresh mount slides were prepared with $0.9 \%$ normal saline solution. Each MPD was obtained at $200 \times-400 \times$ highpower magnification (HPM) via an American Optical 1-10 compound microscope and an OptixCam Summit camera through a diaphragm adapter. Each MPD was cataloged and stored after the specific bacterial culture result was available, and was archived in the computerized database.

The following optic microscopy diagnostic identification criteria (DIC; adapted from López et al) ${ }^{4}$ were used to determine the presence of biofilm formation by lactobacilli: 1) clumping of lactobacilli bacteria - more than 20 lactobacilli per HPM observed; 2) formation of a matrix of lactobacilli, observed as a linear, circular, or semicircular ridge containing more than 30 lactobacilli per HPM; and 3) interaction with vaginal squamous epithelial cells or other bacteria by a group of at least ten lactobacilli per HPM. ${ }^{4}$

Exclusion criteria included absence of lactobacilli in the MPD, number of lactobacilli inferior to the minimum diagnostic required per HPM, presence of clue cells suggesting bacterial vaginosis and/or anaerobic vaginitis, presence of fungal and/or parasites in the MPD, and out-offocus MPD.

Real-time quantitative polymerase chain reaction (qPCR) was used to identify and classify the lactobacilli (Femesis, Women's Research Center, Hamilton, NJ, USA).

A literature search did not reveal any publications regarding this subject (Medline, Embase, Google Scholar, Scopus, Index Medicus [retrieved June 24, 2013 and October 30, 2014]). The query used the words vagina, in vivo, wet mount, lactobacilli, Lactobacillus acidophilus, biofilm formation, vaginal discharge, and recurrent infections, and their possible combinations.

Studying deidentified MPD was not considered to be a human-subject research project by the Texas Tech University

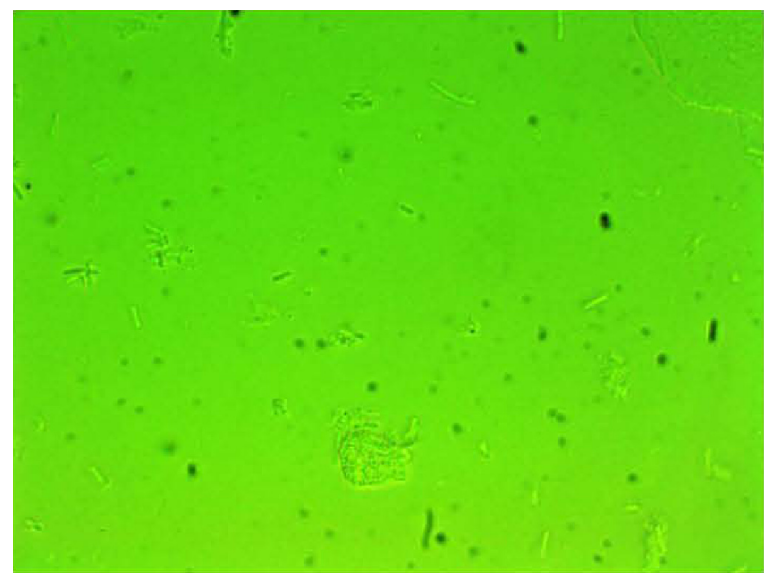

Figure I Clumping of lactobacilli with a matrix formation.

Health Sciences Center Institutional Review Board. Therefore review board approval for this report was not required.

\section{Results}

After our entire database had been reviewed, only 20 MPD from ten different patients were identified. According to the DIC, these 20 MPD were indicative of the presence of lactobacilli forming biofilm in vivo. The 10 MPD were obtained from patients upon completion of appropriate antibiotic treatment, when the test of cure became negative.

MPD Figures 1, 2, and 3 belonged to patients with positive $U$. urealyticum culture. These pictures show clumping of lactobacilli with a matrix formation. MPD Figures 4, 5, and 6 belonged to patients with positive M. hominis culture. These pictures show lactobacilli interaction with vaginal squamous epithelial cells and semicircular ridge formation. MPD Figures 7 and 8 belonged to patients with a history of recurrent bacterial vaginosis by Gardnerella vaginalis. These patients on infertility management

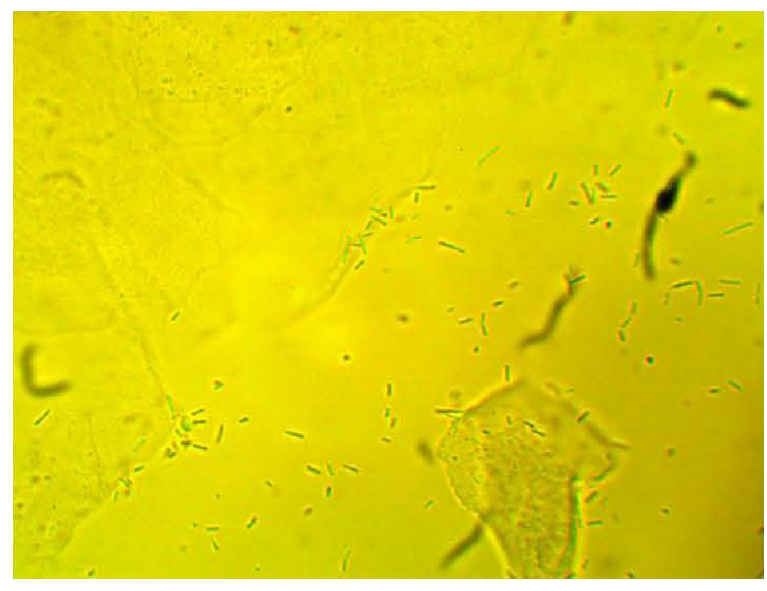

Figure 2 Clumping of lactobacilli with a matrix formation. 


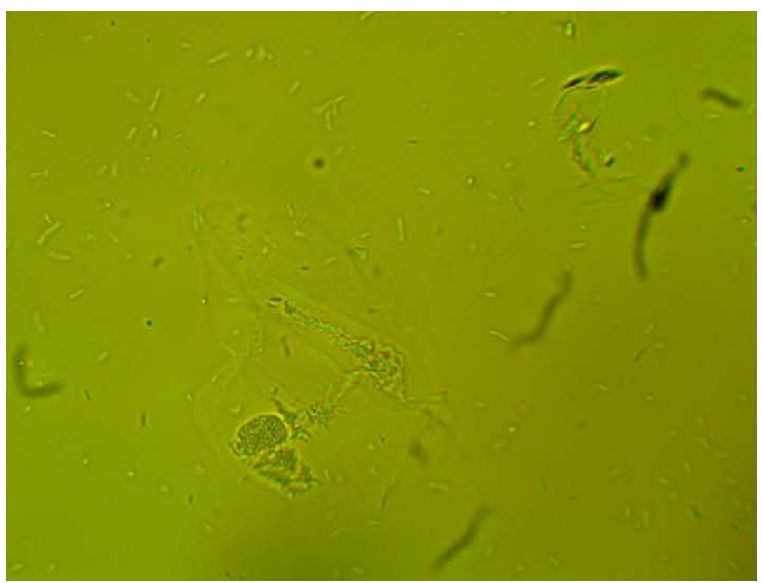

Figure 3 Clumping of lactobacilli with a matrix formation.

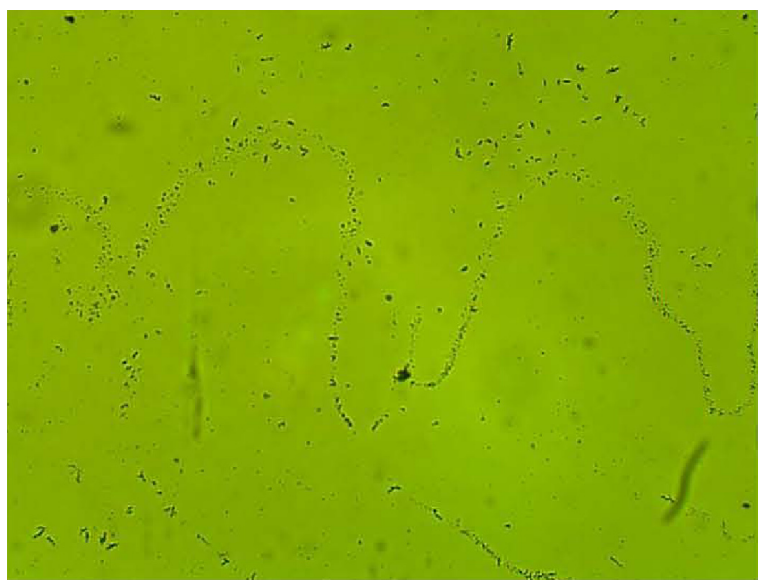

Figure 4 Lactobacilli interaction with vaginal squamous epithelial cells and semicircular ridge formation.

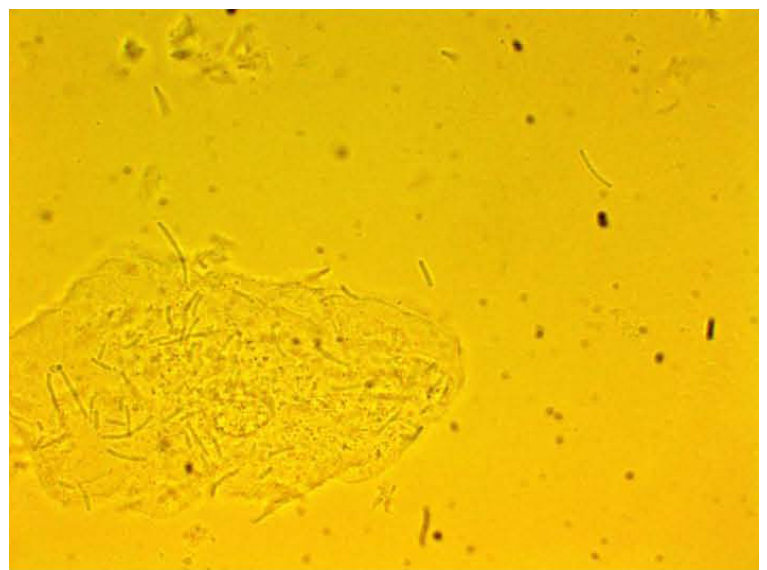

Figure 5 Lactobacilli interaction with vaginal squamous epithelial cells and ridge formation.

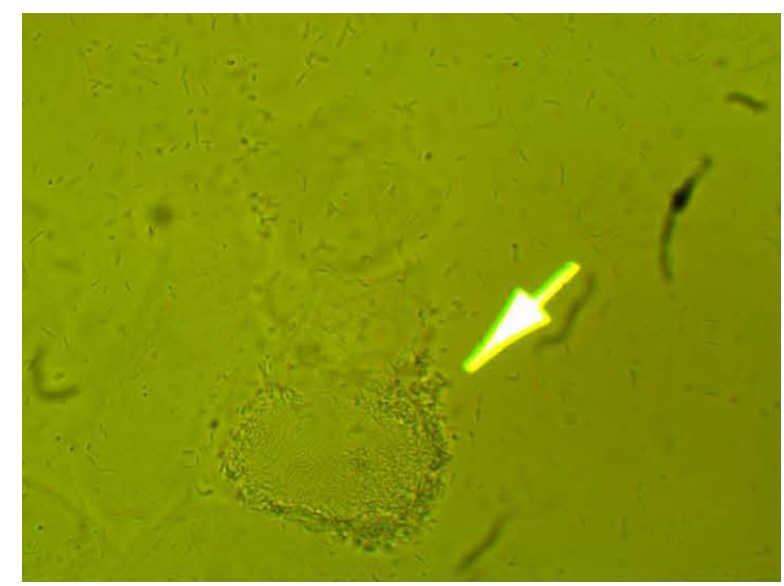

Figure 6 Clumping of lactobacilli with circular ridge formation.

Note: The arrow indicates biofilm.

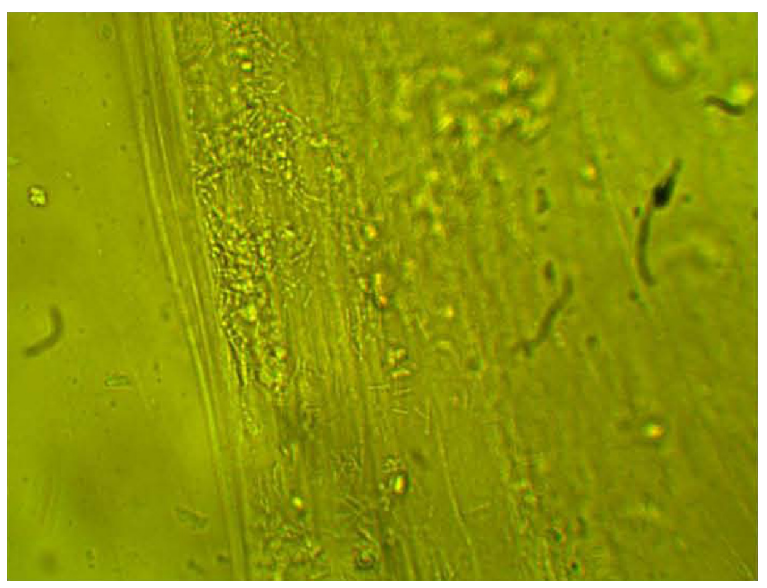

Figure 7 Clumping of lactobacilli: matrix formation with biofilm appearance.

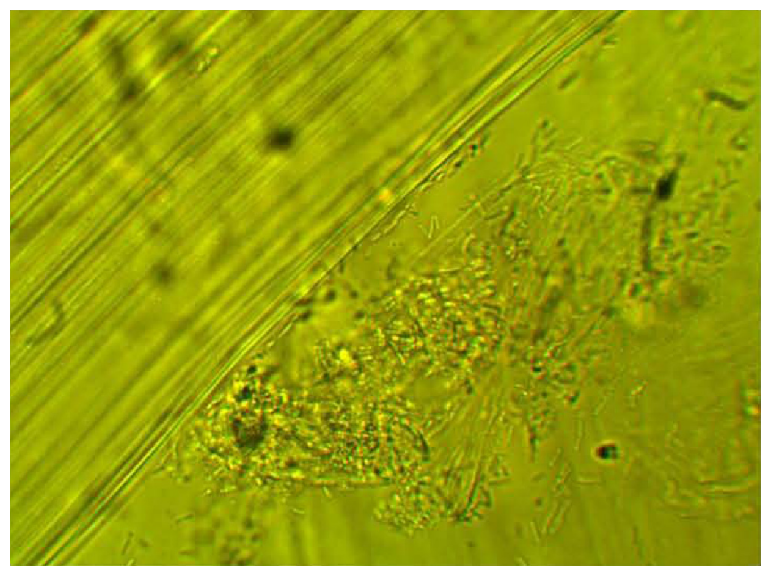

Figure 8 Clumping of lactobacilli: matrix formation with biofilm appearance. 


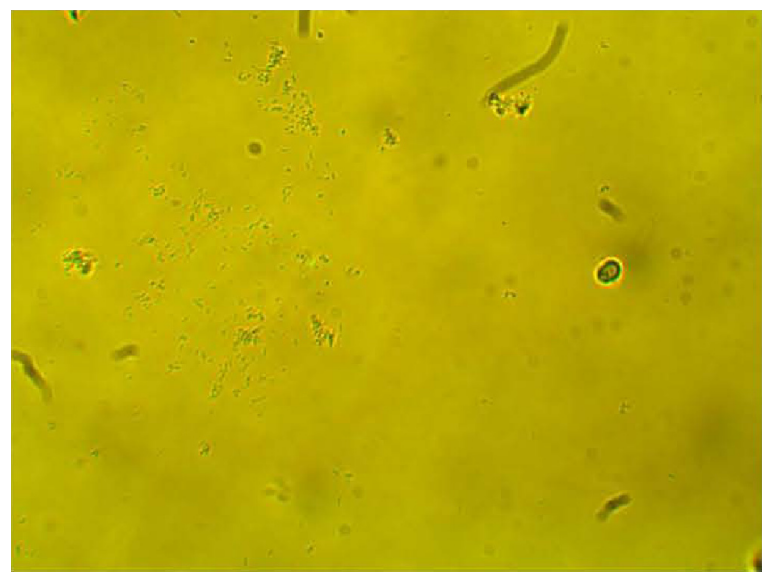

Figure 9 Clumping of lactobacilli with semicircular ridge formation.

were ovulating during a natural menstrual cycle. Their ovulation was diagnosed by a luteinizing hormone surge in their urine. These pictures show clumping of lactobacilli and matrix formation with biofilm appearance. MDP Figures 9 and 10 belonged to patients with positive group B streptococci culture. These pictures show clumping of lactobacilli and semi- and circular ridge formation. The lactobacilli showing formation of biofilm in the $20 \mathrm{MPD}$ from this report were all identified as Lactobacillus jensenii by qPCR technology.

\section{Discussion}

Healthy women normally show in vaginal fluid (Gram-stain smears) a prevalence of lactobacilli microflora composed of Lactobacillus crispatus, Lactobacillus gasseri, Lactobacillus jensenii, and Lactobacillus iners. ${ }^{5}$ Lactobacilli support and maintain a vigorous ecosystem by producing lactic acid, hydrogen peroxide, and bacteriocins. These products have antibacterial properties against vaginal pathogens. Some

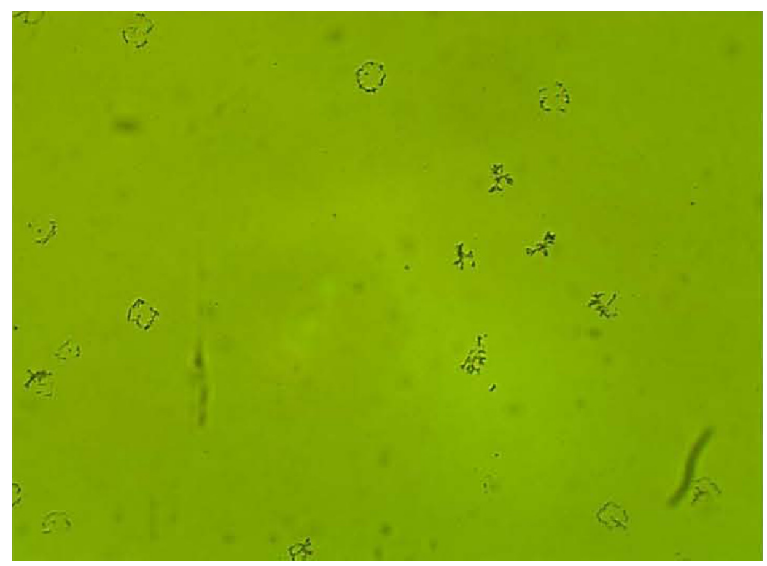

Figure 10 Clumping of lactobacilli with semicircular ridge formation.
Lactobacillus spp. also produce in vitro a thick, protective biofilm utilized to protect them from harmful microbe proliferation. ${ }^{6}$

In the up-to-date medical literature, in vivo formation of biofilm by lactobacilli in fresh wet-mount vaginal preparations has not been reported. This is the first report documenting in vivo formation of biofilm in fresh wet-mount preparations using DIC. These equivalent criteria were used before to document biofilm formation by pathogenic bacteria. ${ }^{4}$

Recently, Terraf et al reported that vaginal biofilm formation was meaningfully influenced by the lactobacilli strain, concentration, bacterial growth, and chemical nature of the culture medium. ${ }^{7}$ Additionally, Leccese Terraf et al published the first study on biofilm formation of vaginal lactobacilli strains (autoaggregation and adhesion) by phenotypic and genetic assays. ${ }^{8}$ Moreover, Zakaria Gomaa reported that all lactobacilli studied produced biofilm on a polystyrene surface, but L. acidophilus displayed the uppermost biofilm formation in Rogosa medium. ${ }^{9}$

The DIC used in this report have been previously validated in research regarding pathogen bacteria. Autoaggregation and adhesion do not occur by chance. The process involves the formation of biofilm. Demonstrating this process in ten different patients, the majority of whom were asymptomatic post-antibiotic therapy complication, is significant.

The MPD from these patients did not show any formation of biofilm by DIC at their initial visit; therefore, the patients served as their own controls. It is also important to point out that $L$. jensenii was the one species identified at qPCR. This finding is in line with the publications by Martín et al, ${ }^{10}$ Terraf et $\mathrm{al}^{7}$ and Leccese Terraf et $\mathrm{al}^{8}$ regarding the ability by $L$. jensenii to form biofilm in vitro.

\section{Clinical implications}

Documenting biofilm formation in fresh wet-mount preparations (in vivo) by vaginal $L$. jensenii is in the author's opinion noteworthy and has significant clinical implications, among which are the possibility to isolate, grow, and possibly utilize therapeutically lactobacilli biofilm to assist in preventing not only recurrent vaginal infections, but more importantly preterm labor associated with vaginal microbial pathogens.

\section{Acknowledgments}

The author thanks Scott Gigax, PhD, Femesis, Women's Research Center, Hamilton, NJ, USA, for the qPCR lactobacilli identification, and Gladys Olivas, for secretarial assistance regarding this manuscript. 


\section{Disclosure}

The author reports no conflict of interest in this work.

\section{References}

1. Costerton JW, Lewandowski Z, Caldwell DE, Korber DR, Lappin-ScottHM. Microbial biofilms. Аnпи Rev Microbiol. 1995;49:711-745.

2. Lepargneur JP, Rousseau V. [Protective role of the Doderlein flora] J Gynecol Obstet Biol Reprod (Paris). 2002;31:485-494. French.

3. Swidsinski A, Mendling W, Loening-Baucke V, et al. Adherent biofilms in bacterial vaginosis. Obstet Gynecol. 2005;106:1013-1023.

4. López D, Vlamakis H, Kolter R. Biofilms. Cold Spring Harb Perspect Biol. 2010;2:a000398.

5. Ventolini G. New insides on vaginal immunity and recurrent infections. J Genit Syst Disord. 2013;2:1.
6. Ventolini G. Update on vaginal lactobacilli and biofilm formation. J Bacteriol Mycol. 2014;1:2.

7. Terraf MC, Juárez Tomás MS, Nader-Macías ME, Silva C. Screening of biofilm formation by beneficial vaginal lactobacilli and influence of culture media components. J Appl Microbiol. 2012;113:1517-1529.

8. Leccese Terraf MC, Mendoza LM, Juárez Tomás MS, Silva C, NaderMacías ME. Phenotypic surface properties (aggregation, adhesion and biofilm formation) and presence of related genes in beneficial vaginal lactobacilli. J Appl Microbiol. 2014;117:1761-1772.

9. Zakaria Gomaa E. Antimicrobial and anti-adhesive properties of biosurfactant produced by lactobacilli isolates, biofilm formation and aggregation ability. J Gen Appl Microbiol. 2013;59:425-436.

10. Martín R, Soberón N, Vaneechoutte M, Flórez AB, Vázquez F, Suárez JE. Characterization of indigenous vaginal lactobacilli from healthy women as probiotic candidates. Int Microbiol. 2008;11:261-266.
International Journal of Women's Health

\section{Publish your work in this journal}

The International Journal of Women's Health is an international, peerreviewed open-access journal publishing original research, reports, editorials, reviews and commentaries on all aspects of women's healthcare including gynecology, obstetrics, and breast cancer. The manuscript management system is completely online and includes

\section{Dovepress}

a very quick and fair peer-review system, which is all easy to use. Visit http://www.dovepress.com/testimonials.php to read real quotes from published authors.

\footnotetext{
Submit your manuscript here: http://www.dovepress.com/international-journal-of-womens-health-journal
} 